\title{
Geotechnical Behavior of Stabilized Dunes Sand by Cement
}

\author{
Mohamed B. D. Elsawy ${ }^{1,2}$ \\ 1. Geotechnical Engineering and Foundations at Department of Civil Engineering, University of Tabuk, Faculty \\ of Engineering, P.O. Box 741, Tabuk 71491, Saudi Arabia \\ 2. On leave from Department of Civil Engineering, Faculty of Engineering, Aswan University, Aswan, Egypt \\ E-mail: melsawy@ut.edu.sa
}

Received: 26 December 2020; Accepted: 28 January 2021; Available online: 25 February 2021

\begin{abstract}
The dunes sand is wide spread with huge quantities all over the world especially in desert areas near roads. The objective of the current paper is to use dunes sand as a foundation soil under structures instead of utilizing expensive replacement with structural fills. The dunes sand samples were collected from a site outside Tabuk city in the north-west of Saudi Arabia. Several experimental tests were performed on the dunes sand samples such as sieve analysis, standard Proctor compaction, drained direct shear and CBR. The test results indicated that the sand dunes are SP according to USCS. The sand dunes have also low shear strength and CBR value. The bearing ability of the sand dunes became weaker due to water immersion. Therefore, the construction on the nontreated dunes sand is impossible. For the later reason, the dunes sand was stabilized with various ordinary Portland cement fractions ranging from 3\% to $15 \%$. Compaction and CBR tests were conducted on the stabilized dunes sand. The maximum dry density increased as the increments of the cement contents accompanying with the decrement of porosity and optimum moisture content. The stabilized dunes sand implied higher CBR values than the non-treated soil. The CBR values of the stabilized soil increased with increasing cement fractions. The stabilized dunes sand induced very high CBR values after longer curing times for all the utilized cement contents. The stabilized dunes sand using only $3 \%$ is considered the optimum design achieving good performance under structures and best economic mix.
\end{abstract}

Keywords: Dunes sand; Cement; Compaction; Shear strength; CBR.

\section{Introduction}

The dunes sand exists in open and desert regions all over the world especially in the Middle East. The dunes sand is found with large quantities outside the cities near highway roads and it enters cities during windy weathers causing environmental problems. The dunes sand has been generated from the weathering of rocks. The weathered soils have been transported by wind for long distances. During transportation, the soil grains were subjected to inter-frictions as well as the weightier grains dropped at shorter distance. In order to save the costs of replacement fills transported from resources and protect environment, the dunes sand should be examined to be utilized as a foundation soil. Few researchers studied the dunes sand [1-7] and they found that the dunes sand has poor geotechnical properties. Generally, the dunes sand was classified as poorly graded sand having usually uniform grain sizes of sand. The fine soil in the dunes sand is non-plastic. The dunes sand has a poor cohesion parameter of the shear strength. Moreover, some dunes sand induces collapsible behavior when immersed with water [3-5]. Trials of utilizing dunes sand as a foundation soil under structures especially highway roads are somewhat recent. But the natural dunes sand can't be used as a foundation soil.

The dunes sand was stabilized by several materials such as bentonite and lime [8], lime and silica fume [9-10], oil residue [11], fibers and geosynthetics [12-14], and cement [15-17]. The stabilization aimed to improve the performance of dunes sand under structures. The most effective stabilizing material for dunes sand is the cement [12]. Another researcher stabilized dunes sand utilizing cement and silica fume [18]. Stabilizing dunes sand improves effectively its bearing ability. Therefore, few researchers studied the behavior of the non-stabilized and stabilized dunes sand especially with cement. The optimum design percent of cement in dunes sand is needed to be determined considering economical side. In the current research, the geotechnical characteristics of a dunes sand are outlined. The validity of using the non-treated dunes sand under structures is examined especially under immersion condition. Moreover, stabilization of dunes sand with different contents of cement is studied. Consequently, the optimum design fraction of cement in dunes sand is selected.

Several geotechnical tests have been performed on the non-treated soil including natural water content, specific gravity, particle size distribution, standard Proctor compaction, direct shear strength and CBR. In order to examine 
the collapse behavior of the dunes sand, additional direct shear and CBR tests have been carried out on the immersed dunes sand. Normally Portland cement has been utilized as a stabilization for dunes sand to enhance its performance under structures. Standard Proctor compaction and CBR tests have been conducted on the stabilized dunes sand with cement fractions ranging from 3\% to 15\% to determine the optimum design mixture.

\section{Materials and test methods}

The dunes sands were collected from a site in Tabuk city located in the north-west of Kingdom of Saudi Arabia. The site coordination is $28^{\circ} 23^{\prime} 48^{\prime \prime} \mathrm{N} 36^{\circ} 25^{\prime} 32.2^{\prime \prime} \mathrm{E}$ as shown in figure 1. Natural geotechnical tests were performed on the dunes sand samples like water content, specific gravity, sieve analysis, and liquid and plastic limits for the fine soil in the sample.

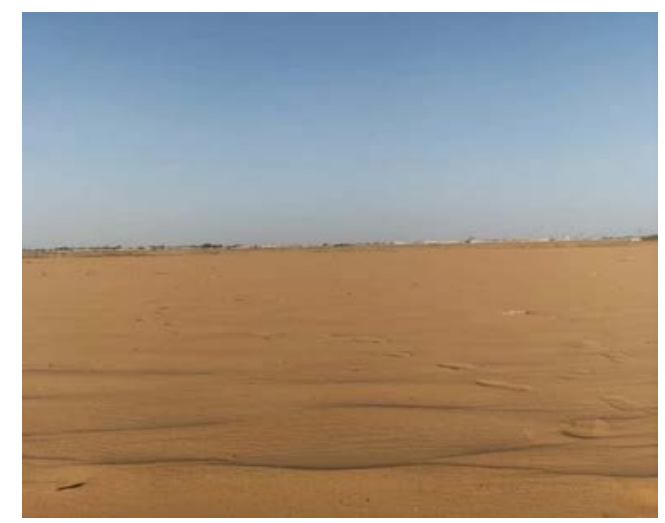

Fig. 1. Site of the dunes sand

Standard Proctor compaction tests were conducted on the non-treated and treated dunes sand by cement. Cement fractions by weight were utilized which are $3 \%, 6 \%, 9 \%, 12 \%$ and $15 \%$. The used cement is ordinary Portland cement (OPC) produced from Tabuk factory. In the preparation of each mixture of sand-cement, the sand and the dry powder of cement were homogenously mixed resulting in same color of the whole mixture. After that, the water was added to the stabilized soil and mixed till reaching homogenous color. Then each mixture was compacted.

Drained direct shear and California bearing ratio (CBR) tests were carried out on the non-treated sand. In order to study the influence of soaking on the bearing ability of dunes sand, direct shear and CBR tests were also performed on soaked dunes sand samples. The samples of dunes sand were soaked before the test for a period of 24 hours. Moreover, CBR tests were conducted on the stabilized dunes sand with different cement ratios under soaking conditions. In order to investigate the curing time on the bearing ability of treated dunes sand, CBR tests were carried out on them after a week curing period. The direct shear test couldn't be performed on the stabilized dunes sand because the stabilized sand samples were noticed hard to be broken by direct shear apparatus. The direct shear and the CBR test were conducted on the non-treated and the treated dunes sand samples according to the results of the compaction tests.

\section{Test results and discussions}

The dunes sand has a $0.3 \%$ water content confirming that the soil is near the dry state. The specific gravity of the dunes sand is 2.63. Based on the sieve analysis test, the particle size distribution curve was drawn as depicted in figure 2. The dunes sand consists of $99.1 \%$ sand and $0.9 \%$ fine soil. According to the Unified Soil Classification System (USCS), the dunes sand is poorly graded sand (SP). The fine soil in the dunes sand is non-plastic which fine sand is. Therefore, the dunes sand consists of fine, medium and coarse sand grains as illustrated in Fig. 2

\subsection{Shear strength characteristics of the non-treated dunes sand}

The compacted non-soaked dunes sand induces low shear strength parameters. The non-soaked dunes sand possesses a zero cohesion and a friction angle of $9.31^{\circ}$. Hence, the studied dunes sand is a pure cohesionless soil. This is because of the dunes sand consists only from sandy soil. Moreover, the opened areas in the kingdom of Saudi Arabian and windy weathers with different speeds have led to traveling and moving dunes sand to long distances. During the dunes sand particles moving, they have been subjected to a lot of friction between grains. The later reasons make the dunes sands have not any cohesion between their particles. 
After immersing of the compacted dunes sand, the shear strength envelope decreases as illustrated in Fig. 3. Consequently, the cohesion of the dunes sand stilled zero while the friction angle decreases from $9.28^{\circ}$ to $4.73^{\circ}$. Therefore, the studied dunes sand implies a collapsible behavior under the water immersion. The collapse behavior of the dunes sand by immersion is due to the reduction of its shear strength to approximately the half. Utilizing non-treated dunes sand as a foundation soil under structures is a risk due to its low shear strength especially after immersion. The dunes sand should be treated by cementing stabilization material to bind between its particles like ordinary Portland cement.

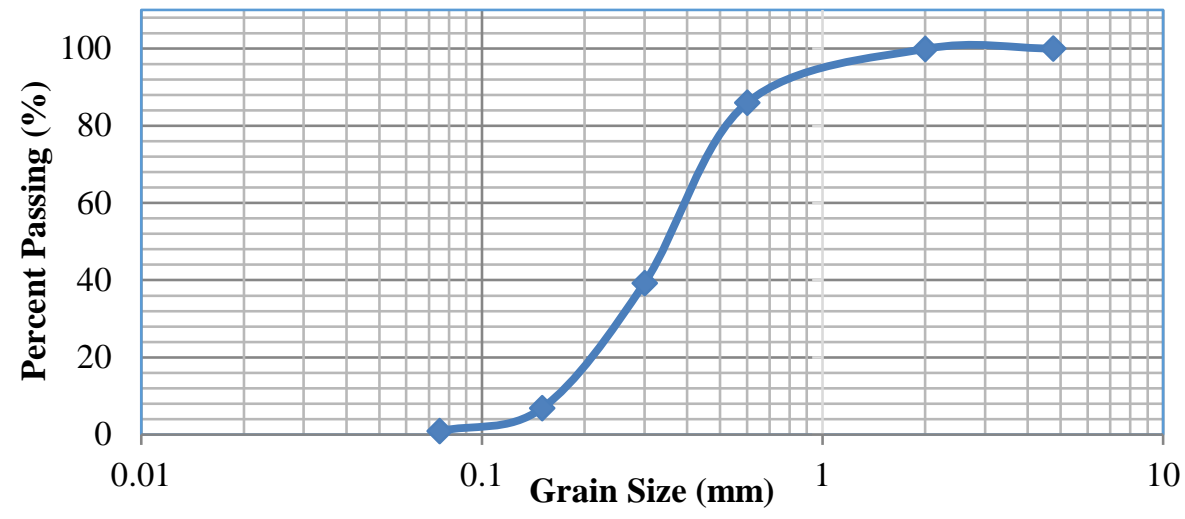

Fig. 2. Grain size distribution curve of dunes sand.

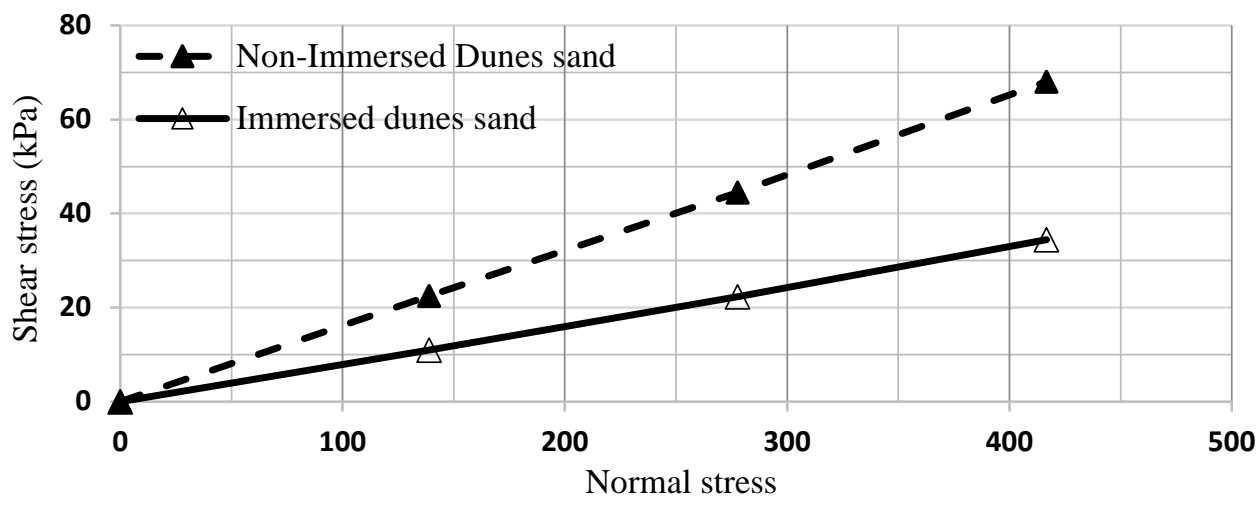

Fig. 3. Shear strength envelopes of the non-immersed and the immersed dunes sand.

\subsection{Effect of cement stabilization on the compaction of the dunes sand}

The compaction curves were drawn for the non-treated and the treated dunes sand with cement fractions of 3\%, $6 \%, 9 \%, 12 \%$ and $15 \%$ as indicated in Fig. 4. The non-stabilized dunes sand induces a maximum dry density of $16.92 \mathrm{kN} / \mathrm{m}^{3}$ and an optimum moisture content of $12.5 \%$. Once, the dunes sand is stabilized by $3 \%$ of OPC, the maximum dry density increases and the optimum moisture content decreases. The increase of the maximum dry density and the reduction in the optimum moisture content continue with increasing OPC content in the sandy soil. The largest maximum dry density and the smallest optimum moisture content occur when utilizing highest OPC percentage on dunes sand as also illustrated in Figs. 5 and 6.

The reduction rate of the optimum moisture content is approximately linear. While the increment rate of the maximum dry density is the greater at the smaller cement percentages which are between cement contents from $3 \%$ to $9 \%$. Beyond the later cement fractions, the rate decreases. The increment of the maximum dry density is attributable to entering the cement powder in the voids of sandy soil during compaction. Once the dunes sand is stabilized with 3\% OPC, an important reduction in the porosity occurred. The porosity reductions continue with the increase of cement percentage in the stabilized sand as illustrated in Fig. 7. The reduction rate of the porosity is the greater at the smaller cement fractions. Therefore, the porosity decreases with the increase of cement content in the stabilized dunes sand. Hence, the greater the cement fraction in the dunes sand is, the smaller the porosity is and the greater the maximum dry density is. Consequently, the optimum moisture contents decrement with increasing cement fraction in the stabilized dunes sand is because of the consumed water in the chemical reaction of the cement. The consumed water increases with increasing cement dosage in the stabilized soil which makes the stabilized dunes sand harder. The greater the cement fraction in the stabilized soil is, and the smaller the optimum moisture content is the harder the stabilized soil is. 


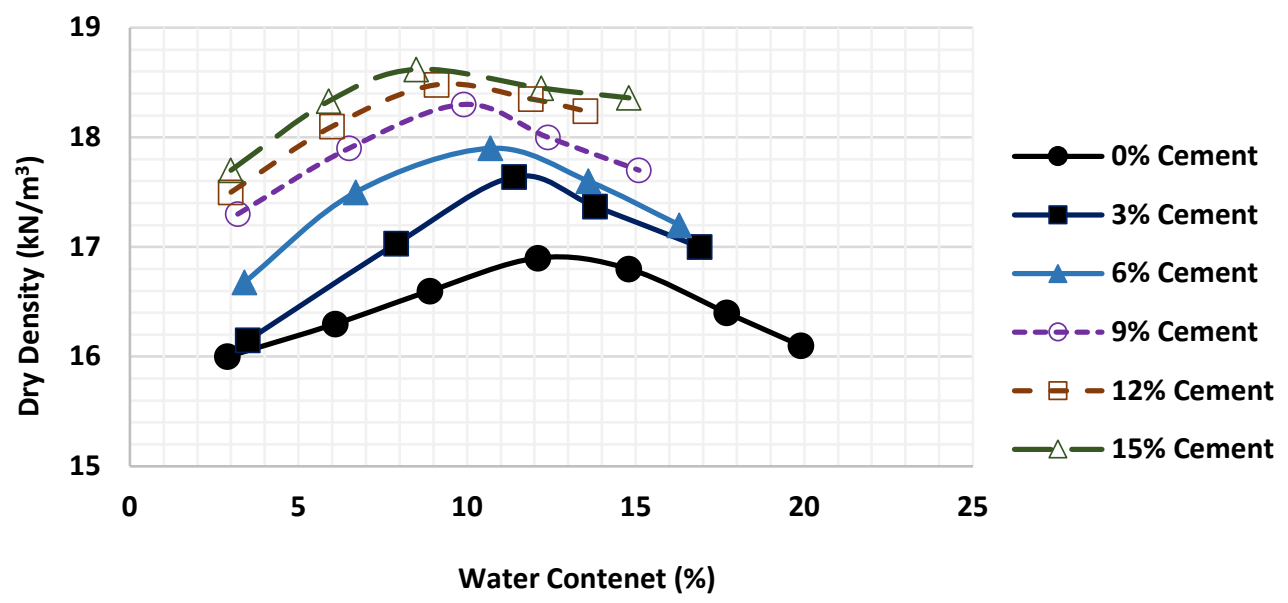

Fig. 4. Compaction curves of the non-treated and treated dunes sand with different fractions of OPC.

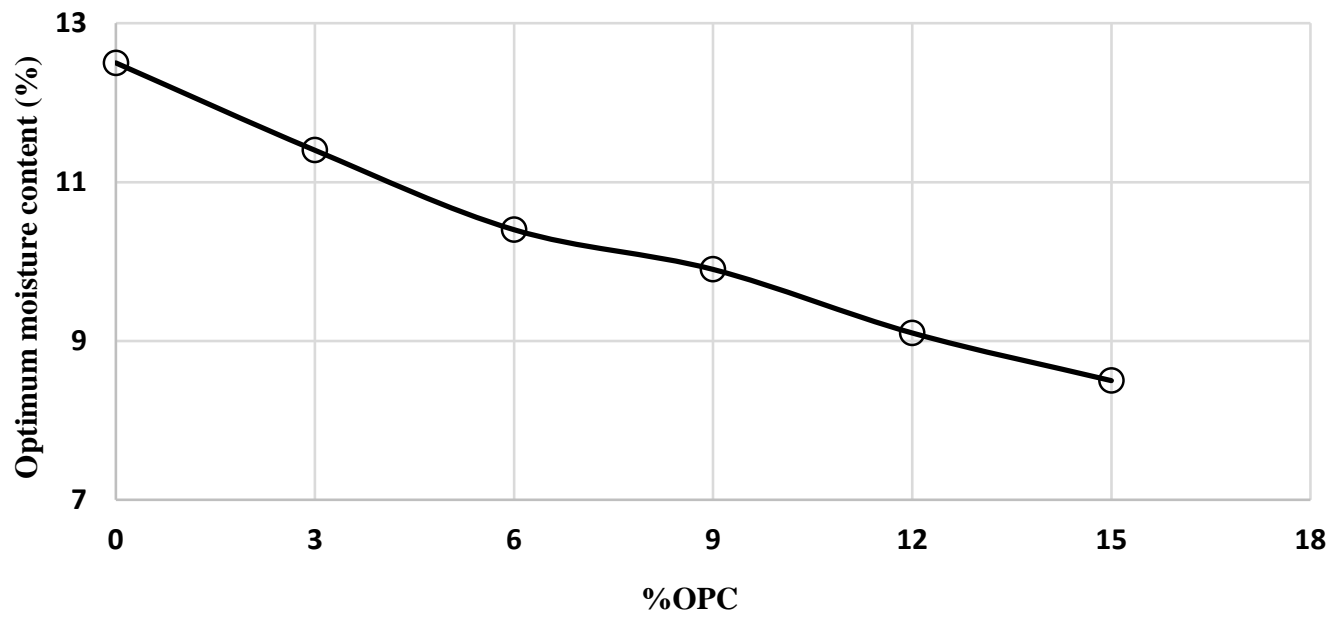

Fig. 5. Variation of optimum moisture content with fractions of OPC.

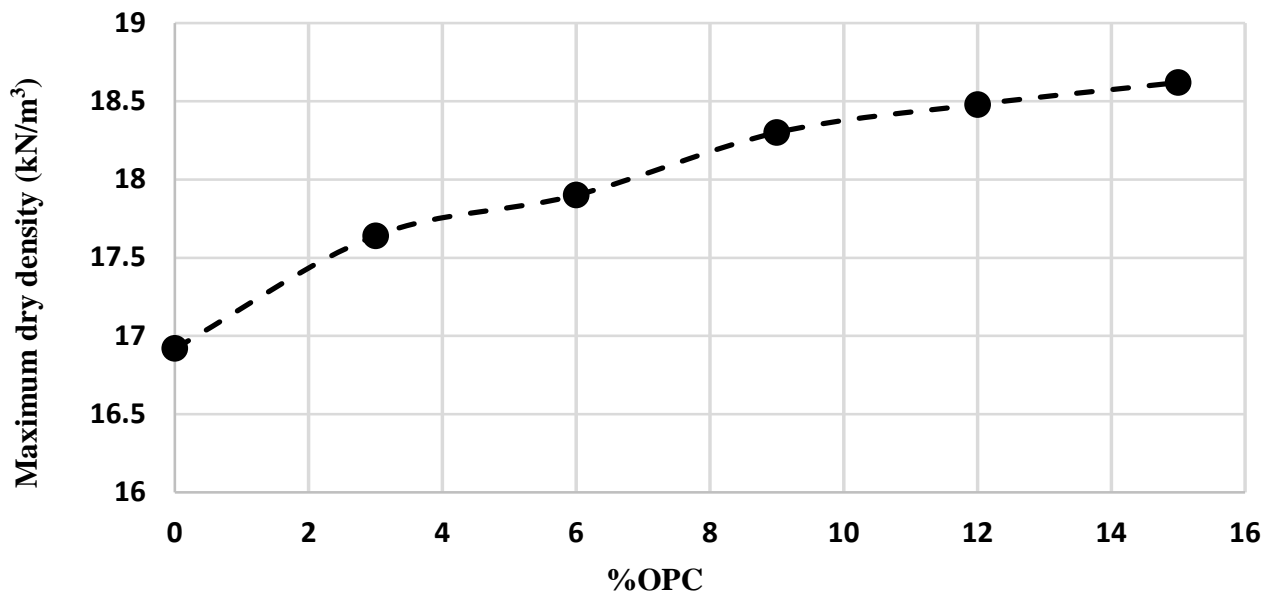

Fig. 6. Variation of maximum dry density with fractions of OPC.

\subsection{Effect of cement stabilization on the CBR values of the dunes sand}

CBR tests were conducted on non-soaked and soaked samples of dunes sand to ensure the effect of immersion.

The non-soaked dunes sand has CBR value of $2 \%$ which is very low to construct on it. After soaking, the CBR decreases to a value of $0.8 \%$. The results of CBR tests confirmed that the dunes sand implies a collapsible behavior after immersion agreeing well with the results of shear strength tests. Therefore, construction light loads infrastructures, like highway roads, couldn't also be applied on the non-treated dunes sand due to it low bearing 
ability. For the later reason, additional CBR tests were performed on treated dunes sand samples with OPC fractions of $3 \%, 6 \%, 9 \%, 12 \%$ and $15 \%$. The treated samples were soaked before testing. Once the dunes sand is stabilized by $3 \%$ cement, the stabilized sand has a significant increment of CBR values. The CBR increases to more than 50 times of that for the non-treated dunes sand. The increase of CBR values continues until reaching a maximum value at the stabilized dunes sand with $15 \%$ as shown in figure 8 . The stabilized dunes sand with $15 \%$ cement has more than 100 times and the twice that of the non-treated dunes sand and the stabilized dunes sand with $3 \%$, respectively. In spite of the CBR values of the dunes sand are significantly enhanced but it isn't still valid to be utilized under highway roads. Based on the later, the influence of cement chemical reaction on CBR values of the stabilized dunes soil should be investigated. The chemical reaction and hardening of cement are dependent on temperature and time in the existence of water.

In order to study the influence of curing time, soaked CBR tests were also carried out on the treated sand dunes with OPC for 7 days. There are significant higher CBR values of the stabilized dunes sand for all the used cement fractions as illustrated in Fig. 8. The CBR values after curing time of 7 days of the stabilized with cement fractions of $3 \%, 6 \%, 9 \%, 12 \%$ and $15 \%$ increase from 10.4 to $96.1,12.9$ to $175,15.8$ to $265.9,20.3$ to 300 and 22 to 357.7 when compared with those after 0 days, respectively. The increment rate of CBR is constant between cement fraction from $0 \%$ and $9 \%$. Beyond $9 \%$ percentage of cement, the increment rate of CBR reduces. The increment rate of CBR is matching well with that of the maximum dry density trend. Hence, the stabilized dunes sand with $9 \%$ content of cement is the optimum design from the economical side. For more economical purposes, the cement percentage of $3 \%$ is sufficient in different highway roads layers. Hence, the stabilized sand dunes with $3 \%$ cement can be utilized in a subgrade layer instead of the expensive replacement structural fill especially the bearing ability of the stabilized soil increases at longer times. Moreover, the later stabilized dunes sand can also be used in the roads layers of base and subbase as a fine aggregate.

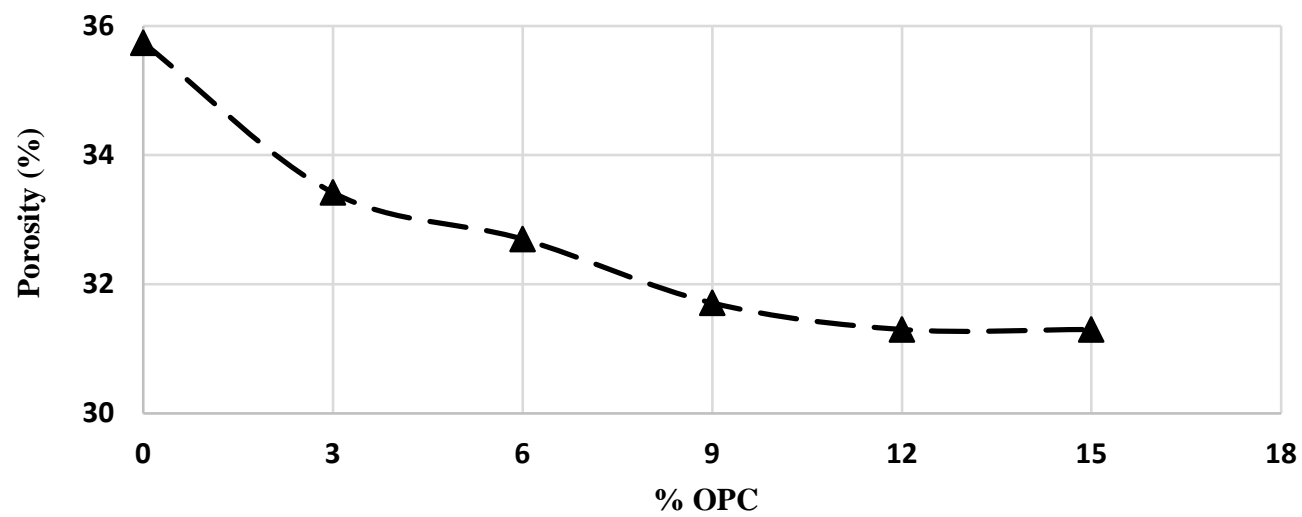

Fig. 7. Variation of porosity with fractions of OPC.

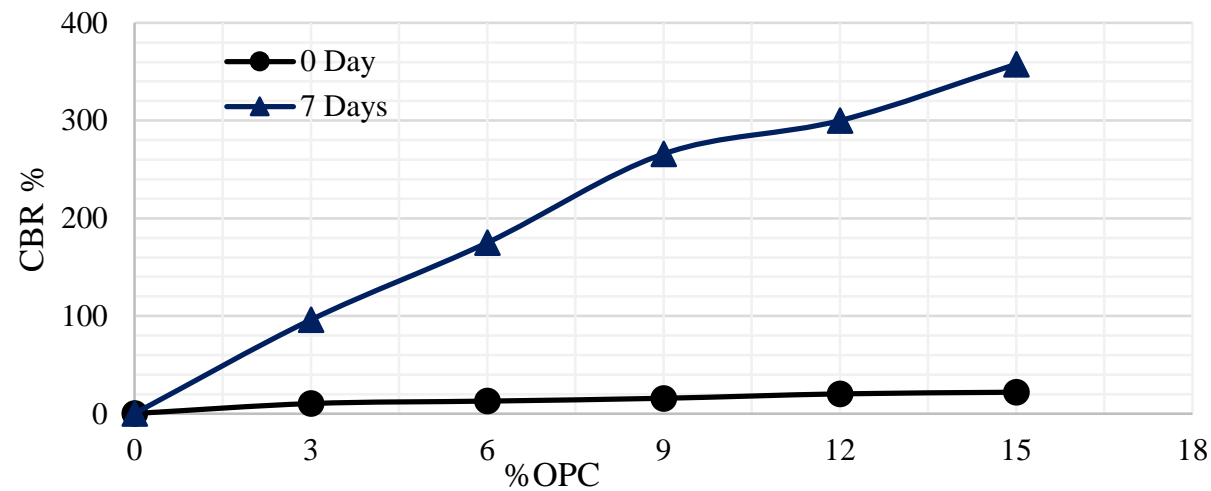

Fig. 8. Variation of CBR of the stabilized dunes sand with fractions of OPC after times of 0 and 7 days.

\section{Conclusions}

Several experimental tests were conducted on the dunes sand samples from Tabuk city in the north-west of Kingdom of Saudi Arabia to study their geotechnical behavior. Standard compaction and CBR tests were also performed on the non-treated and treated dunes sand samples with different ingredients of cement. Additional 
CBR test were carried out on the stabilized dunes sand samples after 7 days to investigate the effect of curing time on their bearing ability. Based on the obtained results the followings can be concluded:

1) The dunes sand under study mainly consists of fine, medium and coarse sand and it classified as poorly graded sand SP according to USCS. The dunes sand causes environmental problems during windy weather.

2) The dunes sand has poor geotechnical characteristics such as low shear strength and low CBR value. The dunes sand becomes weaker under immersion conditions having collapsible behavior. Therefore, the natural dunes sand can't be utilized as a foundation soil under structures.

3) As increasing cement fraction in the stabilized dunes sand, the maximum dry density increases while the porosity and the optimum moisture content decreases.

4) The increment of cement contents in the stabilized dunes sand results in increasing CBR values after 0 day. But the bearing ability of the stabilized dunes sand is still lower than that required for a foundation soil.

5) Seven days curing time of the stabilized dunes induce very high values of CBR for all the used cement fractions.

6) The stabilized dunes sand with 3\% cement content is the optimum design mix for utilizing it as a foundation soil or in the highway roads layers. Further increment in the bearing ability of the later stabilized dunes sand will be occurred at longer curing times.

\section{References}

[1] A1-Sanad, HA, Ismael NF, Nayfeh AJ. Geotechnical properties of dune sands in Kuwait. Journal of Engineering Geology. 1993;34:45-52.

[2] Al-Harthi AA. Geohazard assessment of sand dunes between Jeddah and Al-Lith, western Saudi Arabia. Journal of Environmental Geology. 2002;42:360-369

[3] Bushra SA, Salem LAK. Bearing capacity of shallow footings resting on dune sand. Journal of Engineering. 2012;18(3):298-308.

[4] Al-Taie AJ, Al-Shakarchi YJ, Mohammed AA. Investigation of geotechnical specifications of sand dune soil: a case study around Baiji in Iraq. IIUM Engineering Journal. 2013;14(2): 121-132.

[5] Sanjay G, Ravi S. Geotechnical characterization of dune sands of the Thar desert. Cengrs Geotechnica Pvt. Ltd., B3/87. 2015.

[6] Muqtadir A, Al-Dughaimi S, Kandil1 ME, Ali A, Dvorkin JP. Elastic and mechanical properties of dune sand: experiments and models. Journal of Geophysical Research: Solid Earth. 2019; 124:7978-7992.

[7] Xia H, Zhang J, Du G, Pan H, Duan W, She X. Aeolian sand bearing capacity in the Mu Us Desert of China based on the California Bearing Ratio. Journal of Engineering Research. 2020;8(1):28-41.

[8] Pratibha P, Ameta NK. Stabilization of dune sand with bentonite and lime. Electronic Journal of Geotechnical Engineering. 2013;18:2667-2674.

[9] Mohammed Y, Fattah HH, Ahmed SA. Compaction and collapse characteristics of dune sand stabilized with lime-silica fume mix. Earth Sciences Research Journal. 2016;20(2):1-8.

[10] Mohammed Y, Fattah HH, Ahmed SA. Strength characteristics of dune sand stabilized with lime-silica fume mix. International Journal of Pavement Engineering. 2018;19(10):874-882.

[11] Aflaki E, Hajiannia A. Stabilization of sand dunes with oil residue: Application to civil engineering construction and environmental implications. J. Cent. South Univ. 2015;22: 3059-3068.

[12] Tiwari SK, Sharma JP, Yadav JS. Behaviour of dune sand and its stabilization techniques. Journal of Advanced Research in Applied Mechanics. 2016;19(1): 1-15.

[13] Kebaili M, Menaa L, Kebaili N, Tabti S, Bedda R, Kabdi F. Development of dune sand by the inclusion of geotextile layers. International Journal of Geotechnical Engineering. 2020;14(5):490-496.

[14] Xia H, Zhang J, Cai J, Pan H, She X. Study on the bearing capacity and engineering performance of aeolian sand. Advances in Materials Science and Engineering. 2020;2020.

[15] AlKarni A, ElKholy SM. Improving geotechnical properties of dune sands through cement stabilization. Journal of Engineering and Computer Sciences. 2012;5(1):1-19.

[16] Santos OFJ, Costa PS, Lopes FMG. Compressive and tensile strength of artificially cemented dune sand. Applied Mechanics and Materials. 2013;343:51-61

[17] Amhadi T, Assaf S, Gabriel J. Assessment of strength development of cemented desert soil. International Journal of Low-Carbon Technologies. 2019; 14:543-549.

[18] Rahman MA, Ahmed A. Use of silica fume in stabilizing cement-dune sand for highway materials. American Journal of Civil Engineering. 2017; 5(1):41-49.

(C) 2021 by the author(s). This work is licensed under a Creative Commons Attribution 4.0 International License (http://creativecommons.org/licenses/by/4.0/). Authors retain copyright of their work, with first publication rights granted to Tech Reviews Ltd. 